\title{
Article \\ A Novel Method for Solving Second Kind Volterra Integral Equations with Discontinuous Kernel
}

\author{
Samad Noeiaghdam ${ }^{1,2, *(\mathbb{D})}$ and Sanda Micula ${ }^{3}(\mathbb{D}$ \\ 1 Industrial Mathematics Laboratory, Baikal School of BRICS, Irkutsk National Research Technical University, \\ 664074 Irkutsk, Russia \\ 2 Department of Applied Mathematics and Programming, South Ural State University, Lenin Prospect 76, \\ 454080 Chelyabinsk, Russia \\ 3 Department of Mathematics and Computer Science, Babeş-Bolyai University, 400084 Cluj-Napoca, Romania; \\ smicula@math.ubbcluj.ro or sanda.micula@ubbcluj.ro \\ * Correspondence: snoei@istu.edu or noiagdams@susu.ru
}

Citation: Noeiaghdam, S.; Micula, S. A Novel Method for Solving Second Kind Volterra Integral Equations with Discontinuous Kernel. Mathematics 2021, 9, 2172. https://doi.org/ $10.3390 /$ math 9172172

Academic Editor: Jaan Janno

Received: 4 August 2021

Accepted: 4 September 2021

Published: 5 September 2021

Publisher's Note: MDPI stays neutral with regard to jurisdictional claims in published maps and institutional affiliations.

Copyright: (c) 2021 by the authors. Licensee MDPI, Basel, Switzerland. This article is an open access article distributed under the terms and conditions of the Creative Commons Attribution (CC BY) license (https:/ / creativecommons.org/licenses/by/ $4.0 /)$.

\begin{abstract}
Load leveling problems and energy storage systems can be modeled in the form of Volterra integral equations (VIE) with a discontinuous kernel. The Lagrange-collocation method is applied for solving the problem. Proving a theorem, we discuss the precision of the method. To control the accuracy, we apply the CESTAC (Controle et Estimation Stochastique des Arrondis de Calculs) method and the CADNA (Control of Accuracy and Debugging for Numerical Applications) library. For this aim, we apply discrete stochastic mathematics (DSA). Using this method, we can control the number of iterations, errors and accuracy. Additionally, some numerical instabilities can be identified. With the aid of this theorem, a novel condition is used instead of the traditional conditions.
\end{abstract}

Keywords: Volterra integral equations; Lagrange-collocation method; discrete stochastic mathematics; CESTAC method; CADNA library

\section{Introduction}

Consider the following VIE:

$$
y(x)=f(x)+\sum_{p=1}^{M} \lambda_{p} \int_{\beta_{p-1}(x)}^{\beta_{p}(x)} k_{p}(x, t) y(t) d t, \quad a \leq x, t \leq b,
$$

where the kernel $k_{p}(x, t)$ is discontinuous along continuous curves $\beta_{p}, p=1,2, \ldots, M$ and $f(0)=0, \beta_{0}=a, \beta_{M}=x \leq b$. This problem has many applications in engineering, especially in power systems. In [1], the authors tried to find the parametric solution of VIEs of the first kind. In [2], the authors presented a dynamical study of this problem for applying energy storage (see, for example, [3-5] and the reference therein). In [6,7], the system of VIEs with discontinuous kernels was illustrated. In [8-11], some applications of VIEs to load forecasting and charge/discharge storage controls were analyzed.

There are several methods for solving IEs of the first and second kind, such as the Adomian decomposition method [12], homotopy perturbation method [13], matrix method [14], Taylor collocation method $[15,16]$, homotopy analysis transform method $[17,18]$, homotopy analysis method [19-21], regularization method [22-24], Sinc-collocation method [25,26] and many more [27-30]. The Lagrange-collocation method is one of the most accurate and easily applicable methods for solving different problems. This method was applied for solving time tempered fractional diffusion equations [31], Volterra-Fredholm integral equations [32], multi-frequency oscillatory second-order differential equations [33], high order boundary value problems [34], Hammerstein integral equations [35] and others. 
It should be mentioned that for solving mathematical and engineering problems, we apply the methods, using floating-point arithmetic (FPA). In general form, the precision of these methods should be obtained, using the following condition:

$$
\left|y(x)-y_{n}(x)\right| \leq \epsilon
$$

which depends on the exact solution $y(x)$, the approximate solution $y_{n}(x)$ and $\epsilon$. Finding the exact solution and the optimal $\epsilon$ are the main difficulties of the mentioned condition. Without having the optimal $\epsilon$, extra iterations are produced.

In order to avoid theses problems, we apply the DSA and a novel termination criterion instead of (2). To this aim, the CESTAC method and the CADNA library are handled. Additionally, we do not need to apply the condition (2) and we have the following novel condition:

$$
\left|y_{n}(x)-y_{n-1}(x)\right| \leq @ .0,
$$

where @.0 is the informatical zero, which can be produced only in the CESTAC method. This sign shows the equality between the number of common significant digits (NCSDs) of $y_{n}(x)$ and $y_{n-1}(x)$. For the first time, Laporte and Vignes [36,37] applied this method, and a research group in France developed it [38]. By using this technique, we can find the optimal results, iterations and error of the presented scheme. The CADNA library is the software to write all the CESTAC codes. In this library, we apply C, C++, Fortran or ADA codes. In addition, the Linux operating system should be applied for running the CADNA library. Dynamical control of the Adomian decomposition method [12], homotopy perturbation method [13], homotopy analysis method [20,21,39,40], numerical integration rules [41-45], Sinc-collocation method [25,26], homotopy regularization method [24], Taylor-collocation method [15,16] and many others [46], are some of applications of the mentioned technique.

The rest of the paper is organized as follows: Section 2 focuses on solving the VIE (1), applying the Lagrange-collocation method. Additionally, the error analysis theorem is proved. The CESTAC method and the CADNA library are discussed in Section 3 to validate the obtained numerical results. The main theorem of the method is proved to apply the novel condition (3). In Section 4, we solve some examples and validate the results using the mentioned technique. Based on this procedure, we are able to find the optimal iteration, approximation and error, which are the main novelties of this study. In Section 5, we provide some conclusions.

\section{Lagrange-Collocation Method}

Let

$$
y(x) \simeq y_{n}(x)=\sum_{j=0}^{n} y_{j} l_{j}(x), \quad a \leq x \leq b,
$$

be the approximate solution of Equation (1) where

$$
l_{j}(x)=\prod_{k=0, k \neq j}^{n} \frac{x-x_{k}}{x_{j}-x_{k}}, j=0,1, \ldots, n,
$$

for nodes $a=x_{0}<\ldots<x_{n}=b$. Replacing (4) into (1) leads to the following:

$$
\sum_{j=0}^{n} y_{j} l_{j}(x)=f(x)+\sum_{j=0}^{n} \sum_{p=1}^{M} \lambda_{p} \int_{\beta_{p-1}(x)}^{\beta_{p}(x)} k_{p}(x, t) y_{j} l_{j}(t) d t .
$$

Substituting the collocation nodes $x_{i}=a+\left(\frac{b-a}{n}\right) i, i=0,1, \ldots, n$ in Equation (5), we obtain the following:

$$
\sum_{j=0}^{n} a_{i j} y_{j}=f\left(x_{i}\right), \quad i=0,1, \ldots, n
$$

where 


$$
a_{i j}=l_{j}\left(x_{i}\right)-\sum_{p=1}^{M} \lambda_{p} \int_{\beta_{p-1}\left(x_{i}\right)}^{\beta_{p}\left(x_{i}\right)} k_{p}\left(x_{i}, t\right) y_{j} l_{j}(t) d t, \quad i, j=0,1, \ldots, n .
$$

Thus, solving the following system,

$$
A Y=F,
$$

where

$$
\begin{gathered}
A=\left(a_{i j}\right)_{(n+1)(n+1),} \\
Y=\left(y_{0}, y_{1}, \ldots, y_{n}\right)^{T}, \\
F=\left(f\left(x_{0}\right), f\left(x_{1}\right), \ldots, f\left(x_{n}\right)\right)^{T},
\end{gathered}
$$

the $n$-th order approximate solution of the VIE with discontinuous kernel (1) based on the Lagrange polynomials can be obtained in the form of $y_{n}(x)=\sum_{j=0}^{n} y_{j} l_{j}(x)$.

Theorem 1. Let $f(x)$ be a function defined on $[a, b]$ and $k_{p}, p=1,2, \ldots, M$ be sufficiently smooth continuous on $[a, b] \times[a, b]$. Let $y(x)$ be the exact solution of (1), which is assumed to be arbitrarily differentiable, and $y_{n}(x)$ the $n$-th order Lagrange collocation solution of (7). We obtain the following:

$$
\left\|y(x)-y_{n}(x)\right\|_{\infty} \leq \frac{S}{(n+1) !} \max _{a \leq x \leq b}\left|y^{(n+1)}(x)\right|+C \max _{a \leq x_{j} \leq b}\left|e\left(x_{j}\right)\right|
$$

where $S=\max _{a \leq x \leq b}\left|w_{n+1}(x)\right|, C=\|l\|_{\infty}=\max _{a \leq x \leq b}\left\{\left|l_{0}(x)\right|,\left|l_{1}(x)\right|, \ldots,\left|l_{n}(x)\right|\right\}, e\left(x_{j}\right)=$ $y\left(x_{j}\right)-y_{n}\left(x_{j}\right)$.

Proof. For the exact and approximate solutions $y(x)$ and $y_{n}(x)$, we obtain the following:

$$
\left\|y(x)-y_{n}(x)\right\|_{\infty} \leq\left\|y(x)-l_{n}(x)\right\|_{\infty}+\left\|l_{n}(x)-y_{n}(x)\right\|_{\infty},
$$

where

$$
l_{n}(x)=\sum_{j=0}^{n} y\left(x_{j}\right) l_{j}(x), \quad y_{n}(x)=\sum_{j=0}^{n} y_{j} l_{j}(x)
$$

are the interpolation function and the approximate solution of (1), respectively.

By writing the remainder term of the interpolation polynomial as $R_{n}(x)=y(x)-$ $l_{n}(x)=\frac{y^{(n+1)}}{(n+1) !} w_{n+1}(x)$, we can write the following:

$$
\left|R_{n}(x)\right| \leq \frac{1}{(n+1) !} \max _{a \leq x \leq b}\left|y^{(n+1)}(x)\right| \max _{a \leq x \leq b}\left|w_{n+1}(x)\right|=\frac{S}{(n+1) !} \max _{a \leq x \leq b}\left|y^{(n+1)}(x)\right| .
$$

By denoting $\delta_{n}=\left(e\left(x_{0}\right), e\left(x_{1}\right), \ldots, e\left(x_{j}\right), \ldots, e\left(x_{n}\right)\right)^{T}$ and $l=\left(l_{0}(x), l_{1}(x), \ldots, l_{n}(x)\right)^{T}$, we obtain the following:

$$
\left|l_{n}(x)-y_{n}(x)\right|=\left|\sum_{j=0}^{n}\left(y\left(x_{j}\right)-y_{j}\right) l_{j}(x)\right|=\left|\delta_{n} l\right| \leq\left\|\delta_{n}\right\|_{\infty}\|l\|_{\infty} \leq C\left\|\delta_{n}\right\|_{\infty},
$$

where $e\left(x_{j}\right)=y\left(x_{j}\right)-y_{n}\left(x_{j}\right)$.

Using Equations (8) and (9), we can write the following:

$$
\begin{aligned}
& \left\|y(x)-y_{n}(x)\right\|_{\infty} \leq \frac{1}{(n+1) !} \max _{a \leq x \leq b}\left|y^{(n+1)}(x)\right| \max \left|w_{n+1}(x)\right|+\|l\|_{\infty}\left\|\delta_{n}\right\|_{\infty} \\
& =\frac{S}{(n+1) !} \max _{a \leq x \leq b}\left|y^{(n+1)}(x)\right|+C \max _{a \leq x_{j} \leq b}\left|e\left(x_{j}\right)\right| .
\end{aligned}
$$




\section{CESTAC Method and CADNA Library}

In order to apply the CESTAC method, we need to use the SA; generally, we utilize this method to control the accuracy of numerical and iterative methods for solving mathematical and engineering problems $[47,48]$.

Assume that $B$ is a set of representable values by a computer; for $s^{*} \in \mathbb{R}$, we can produce $S^{*} \in B$ with $\alpha$ mantissa bits of the binary FPA as the following:

$$
S^{*}=s^{*}-\rho 2^{E-\alpha} \phi,
$$

where $\rho$ shows the sign, $2^{-\alpha} \phi$ demonstrates the missing segment of the mantissa, and $E$ is the binary exponent of the result. Changing $\alpha$ from 24 to 53, we can change the precision from a single to double form $[49,50]$. Let $\phi$ be a stochastic variable, which is uniformly distributed on $[-1,1]$. Making a perturbation on the last mantissa bit of $s^{*}$, we have the mean $(\mu)$ and the standard deviation $(\sigma)$ for $S^{*}$. Repeating the process for $k$-times, we have $k$ samples of $S^{*}$ as follows:

$$
\Phi=\left\{S_{1}^{*}, S_{2}^{*}, \ldots, S_{k}^{*}\right\} .
$$

Now we can find the mean and standard deviation values as the following:

$$
\tilde{S}^{*}=\frac{\sum_{i=1}^{k} S_{i}^{*}}{k}, \quad \sigma^{2}=\frac{\sum_{i=1}^{k}\left(S_{i}^{*}-\tilde{S}^{*}\right)^{2}}{k-1} .
$$

Thus, we are able to find the NCSDs between $S^{*}$ and $\tilde{S}^{*}$ as the following:

$$
C_{\tilde{S}^{*}, S^{*}}=\log _{10} \frac{\sqrt{k}\left|\tilde{S}^{*}\right|}{\tau_{\delta} \sigma}
$$

where $\tau_{\delta}$ is the value of $T$ distribution, as the confidence interval is $1-\delta$ with $k-1$ freedom degree. When we have

$$
\tilde{S}^{*}=0
$$

or

$$
C_{\tilde{S}^{*}, S^{*}} \leq 0,
$$

the algorithm is stopped by showing $S^{*}=@$.0. It shows that we have equality between the NCSDs of $\tilde{S}^{*}$ and $S^{*}$.

The main difference between this method and other methods is applying the CADNA library instead of mathematical packages, such as MATLAB, Mathematica, Maple. In order to apply this library, we need to use the LINUX operating system. Additionally, we should write all codes using C, C++, FORTRAN or ADA. Applying this method and the library, we can find the optimal approximation, optimal step of the method, optimal error and some of numerical instabilities. They are the main advantages of our method, compared to other methods.

In order to apply the CADNA library, the following sample can be applied:



The function "Strp" should be applied to show the NCSDs. Thus, when the NCSDs become zero, we will see the informatical zero sign @.0, and the algorithm will be stopped. 
Definition 1 ([51]). Let $s_{1}$ and $s_{2}$ be two real numbers. The NCSDs for $s_{1}$ and $s_{2}$ can be defined as follows:

$$
C_{s_{1}, s_{2}}=\left\{\begin{array}{l}
\log _{10}\left|\frac{s_{1}+s_{2}}{2\left(s_{1}-s_{2}\right)}\right|=\log _{10}\left|\frac{s_{1}}{s_{1}-s_{2}}-\frac{1}{2}\right|, \quad s_{1} \neq s_{2}, \\
+\infty, \quad \text { otherwise. }
\end{array}\right.
$$

Theorem 2. Assume that $y(t)$ is the exact solution of the second kind VIE (1), and $y_{n}(t)$ is its approximate solution which is obtained using the Lagrange-collocation method. Then, we have the following:

$$
C_{y_{n}(t), y(t)}-C_{y_{n}(t), y_{n+1}(t)}=\mathcal{O}\left(\frac{1}{(n+1) !}\right) .
$$

Proof. Applying Definition 1, we can write the following:

$$
\begin{aligned}
C_{y_{n}(t), y_{n+1}(t)} & =\log _{10}\left|\frac{y_{n}(t)+y_{n+1}(t)}{2\left(y_{n}(t)-y_{n+1}(t)\right)}\right|=\log _{10}\left|\frac{y_{n}(t)}{y_{n}(t)-y_{n+1}(t)}-\frac{1}{2}\right| \\
& =\log _{10}\left|\frac{y_{n}(t)}{y_{n}(t)-y_{n+1}(t)}\right|+\log _{10}\left|1-\frac{1}{2 y_{n}(t)}\left(y_{n}(t)-y_{n+1}(t)\right)\right| \\
& =\log _{10}\left|\frac{y_{n}(t)}{y_{n}(t)-y_{n+1}(t)}\right|+\mathcal{O}\left(y_{n}(t)-y_{n+1}(t)\right) .
\end{aligned}
$$

Since

$$
y_{n}(t)-y_{n+1}(t)=y_{n}(t)-y(t)-\left(y_{n+1}(t)-y(t)\right)=E_{n}(t)-E_{n+1}(t),
$$

using Theorem 1, we obtain the following:

$$
\mathcal{O}\left(y_{n}(t)-y_{n+1}(t)\right)=\mathcal{O}\left(E_{n}(t)-E_{n+1}(t)\right)=\mathcal{O}\left(\frac{1}{(n+1) !}\right)+\mathcal{O}\left(\frac{1}{(n+2) !}\right)=\mathcal{O}\left(\frac{1}{(n+1) !}\right) .
$$

Therefore, we have the following:

$$
C_{y_{n}(t), y_{n+1}(t)}=\log _{10}\left|\frac{y_{n}(t)}{y_{n}(t)-y_{n+1}(t)}\right|+\mathcal{O}\left(\frac{1}{(n+1) !}\right) .
$$

Furthermore, we have the following:

$$
\begin{aligned}
C_{y_{n}(t), y(t)} & =\log _{10}\left|\frac{y_{n}(t)+y(t)}{2\left(y_{n}(t)-y(t)\right)}\right|=\log _{10}\left|\frac{y_{n}(t)}{y_{n}(t)-y(t)}-\frac{1}{2}\right| \\
& =\log _{10}\left|\frac{y_{n}(t)}{y_{n}(t)-y(t)}\right|+\mathcal{O}\left(y_{n}(t)-y(t)\right) \\
& =\log _{10}\left|\frac{y_{n}(t)}{y_{n}(t)-y(t)}\right|+\mathcal{O}\left(\frac{1}{(n+1) !}\right) .
\end{aligned}
$$

By using Equations (13) and (14), we have the following: 


$$
\begin{aligned}
C_{y_{n}(t), y(t)}-C_{y_{n}(t), y_{n+1}(t)} & =\log _{10}\left|\frac{y_{n}(t)}{y_{n}(t)-y(t)}\right|-\log _{10}\left|\frac{y_{n}(t)}{y_{n}(t)-y_{n+1}(t)}\right|+\mathcal{O}\left(\frac{1}{(n+1) !}\right) \\
& =\log _{10}\left|\frac{y_{n}(t)-y(t)}{y_{n}(t)-y_{n+1}(t)}\right|+\mathcal{O}\left(\frac{1}{(n+1) !}\right) \\
& =\log _{10}\left|\frac{\mathcal{O}\left(\frac{1}{(n+1) !}\right)}{\mathcal{O}\left(\frac{1}{(n+1) !}\right)}\right|+\mathcal{O}\left(\frac{1}{(n+1) !}\right) \\
& =\mathcal{O}\left(\frac{1}{(n+1) !}\right)
\end{aligned}
$$

and we obtain the following:

$$
C_{y_{n}(t), y(t)}-C_{y_{n}(t), y_{n+1}(t)}=\mathcal{O}\left(\frac{1}{(n+1) !}\right) .
$$

Approaching $n$ to infinity, we have $\mathcal{O}\left(\frac{1}{(n+1) !}\right) \rightarrow 0$ and the following:

$$
C_{y_{n}(t), y(t)}=C_{y_{n}(t), y_{n+1}(t)} .
$$

\section{Numerical Examples}

In this section, some examples of VIEs with a discontinuous kernel are discussed. We use the mentioned method using both arithmetics, the FPA and the DSA. In addition, we apply both conditions (2) and (3), and finally, we compare the results to show several benefits of the DSA.

Example 1. Consider the following second kind VIE as follows:

$$
y(x)=f(x)+\int_{0}^{\frac{x}{7}} x t y(t) d t+\int_{\frac{x}{7}}^{\frac{2 x}{7}}(x-1) y(t) d t+3 \int_{\frac{2 x}{7}}^{\frac{4 x}{7}} y(t) d t+\int_{\frac{4 x}{7}}^{x}(x+t) y(t) d t,
$$

where the following holds:

$$
\begin{gathered}
f(x)=e^{x}-3 e^{\frac{2 x}{7}}\left(-1+e^{\frac{2 x}{7}}\right)-e^{\frac{4 x}{7}}\left(1-\frac{11 x}{7}\right)-e^{\frac{x}{7}}\left(-1+e^{\frac{x}{7}}\right)(-1+x) \\
-\left(1+\frac{1}{7} e^{\frac{x}{7}}(-7+x)\right) x-e^{x}(-1+2 x) .
\end{gathered}
$$

Figure 1a shows the comparison between solutions, and Figure $1 b$ shows the error. The results of the FPA can be found in Tables 1 and 2. In Table 2, the steps of the method are obtained for various $\epsilon$. The optimal results are presented in Table 3. According to this table, we have the following:

$$
\begin{aligned}
& n_{\text {opt }}=6, \\
& y_{\text {opt }}(0.2)=1.22140, \\
& \text { error }_{\text {opt }}=0.29 \times 10^{-4}
\end{aligned}
$$




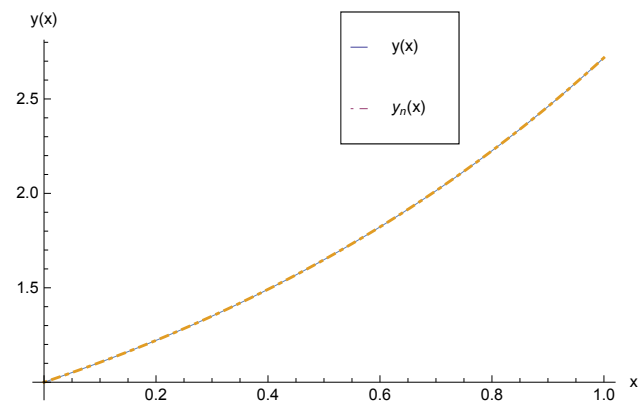

(a)

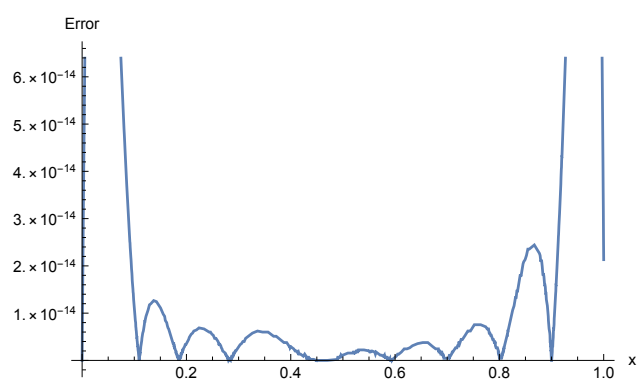

(b)

Figure 1. (a) Comparison between the solutions-(b) error of Example 1 for $n=10$.

Table 1. Applying the FPA for Example 1 with $\epsilon=10^{-5}$ and $x=0.2$.

\begin{tabular}{ccc}
\hline $\boldsymbol{n}$ & $\boldsymbol{y}_{\boldsymbol{n}}(\boldsymbol{x})$ & $\left|\boldsymbol{y}(\boldsymbol{x})-\boldsymbol{y}_{\boldsymbol{n}}(\boldsymbol{x})\right|$ \\
\hline 1 & 3.62968015670776367188 & 2.40827751159667968750 \\
2 & 1.20426642894744873047 & 0.01713633537292480469 \\
3 & 1.22232985496520996094 & 0.00092709064483642578 \\
4 & 1.22137403488159179688 & 0.00002872943878173828 \\
5 & 1.22140347957611083984 & 0.00000071525573730469 \\
\hline
\end{tabular}

Table 2. Applying the FPA to find $n$ for various $\epsilon$ and $x=0.2$.

\begin{tabular}{ccccccc}
\hline$\epsilon$ & $\epsilon<<10^{-8}$ & $\epsilon=10^{-8}$ & $\epsilon=10^{-5}$ & $\epsilon=10^{-3}$ & $\epsilon=10^{-1}$ & $\epsilon>>10^{-1}$ \\
\hline$n$ & $>>7$ & 7 & 5 & 3 & 2 & 1 \\
\hline
\end{tabular}

Table 3. Results of the CESTAC method for Example 1 and $x=0.2$.

\begin{tabular}{cccc}
\hline$n$ & $y_{n}(x)$ & $\left|y_{n}(x)-y_{n-1}(x)\right|$ & $\left|y_{n}(x)-y(x)\right|$ \\
\hline 1 & 3.629679 & 3.629679 & 2.408277 \\
2 & 1.204266 & 2.425413 & $0.17136 \times 10^{-1}$ \\
3 & 1.222329 & $0.1806 \times 10^{-1}$ & $0.926 \times 10^{-3}$ \\
4 & 1.221374 & $0.955 \times 10^{-3}$ & $0.28 \times 10^{-4}$ \\
5 & 1.221403 & $0.29 \times 10^{-4}$ & $@ .0$ \\
6 & 1.22140 & $@ .0$ & $@ .0$ \\
\hline
\end{tabular}

Example 2. Consider the following problem:

$$
y(x)=f(x)+\int_{0}^{\frac{x}{9}}\left(x^{2}-t\right) y(t) d t+\int_{\frac{x}{9}}^{\frac{5 x}{9}} y(t) d t+2 \int_{\frac{5 x}{9}}^{\frac{8 x}{9}} y(t) d t+\int_{\frac{8 x}{9}}^{x} y(t) d t
$$

where

$$
f(x)=x^{3}-\frac{10031 x^{4}}{26244}+\frac{x^{5}}{295245}-\frac{x^{6}}{26244} .
$$

Figure 2 shows the comparative graphs between solutions and also the error function. The results of the FPA for $\epsilon=10^{-1}$ and $x=0.8$ are given in Table 4. Table 5 discusses the iterations for various $\epsilon$. In Table 6, we can find the optimal results as the following:

$$
\begin{aligned}
& n_{\text {opt }}=4 \\
& y_{\text {opt }}(0.8)=0.511999
\end{aligned}
$$




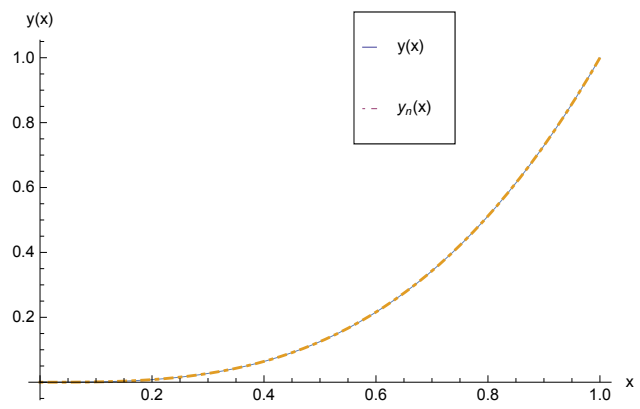

(a)

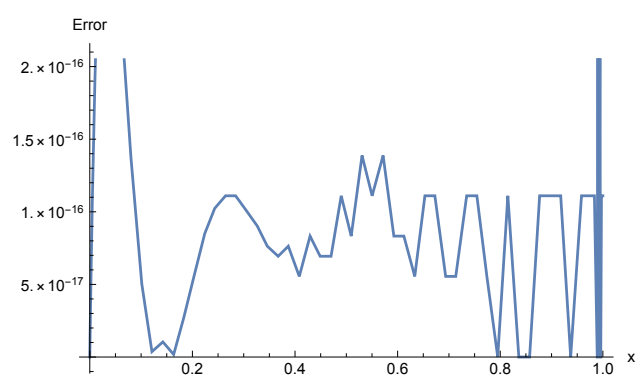

(b)

Figure 2. (a) Comparison between the solutions-(b) error function for $n=10$.

Table 4. Applying the FPA for Example 1 with $\epsilon=10^{-1}$ and $x=0.8$.

\begin{tabular}{ccc}
\hline$n$ & $y_{n}(x)$ & $\left|y(x)-y_{n}(x)\right|$ \\
\hline 1 & 1.90282404422760009766 & 1.39082407951354980469 \\
2 & 0.52353602647781372070 & 0.01153600215911865234 \\
\hline
\end{tabular}

Table 5. Applying the FPA to find $n$ for various $\epsilon$ and $x=0.8$.

\begin{tabular}{ccccccc}
\hline$\epsilon$ & $\epsilon<<10^{-5}$ & $\epsilon=10^{-5}$ & $\epsilon=10^{-3}$ & $\epsilon=10^{-1}$ & $\epsilon=0.5$ & $\epsilon>>0.5$ \\
\hline$n$ & $>>6$ & 6 & 4 & 2 & 1 & 1 \\
\hline
\end{tabular}

Table 6. Results of the CESTAC method for Example 2 and $x=0.8$.

\begin{tabular}{cccc}
\hline$n$ & $y_{n}(x)$ & $\left|y_{n}(x)-y_{n-1}(x)\right|$ & $\left|y(x)-y_{n}(x)\right|$ \\
\hline 1 & 1.902823 & 1.902823 & 1.390824 \\
2 & 0.523535 & 1.379288 & $0.11536 \times 10^{-1}$ \\
3 & 0.5119998 & $0.11536 \times 10^{-1}$ & $@ .0$ \\
4 & 0.511999 & $@ .0$ & $@ .0$ \\
\hline
\end{tabular}

Example 3. Consider the following VIE:

$$
y(x)=f(x)+\int_{0}^{\frac{x}{3}}(1+x-t) y(t) d t+\int_{\frac{x}{3}}^{x} y(t) d t
$$

where

$$
f(x)=-1-x-\cos \frac{x}{3}+\frac{1}{3}(3+2 x) \cos \frac{x}{3}+\cos x+\sin \frac{x}{3}+\sin x .
$$

The accuracy and efficiency of the method are shown in Figure 3 by plotting the comparative graph and the error function for $n=10$ and $x=0.6$. The numerical results of the FPA are presented in Tables 7 and 8. Additionally, in Table 9 the numerical results of the DSA are presented. We obtain the following:

$$
\begin{aligned}
& n_{o p t}=8 \\
& y_{o p t}(0.6)=0.564641
\end{aligned}
$$




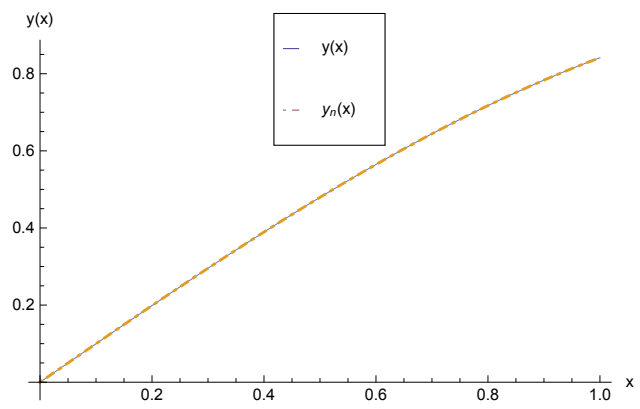

(a)

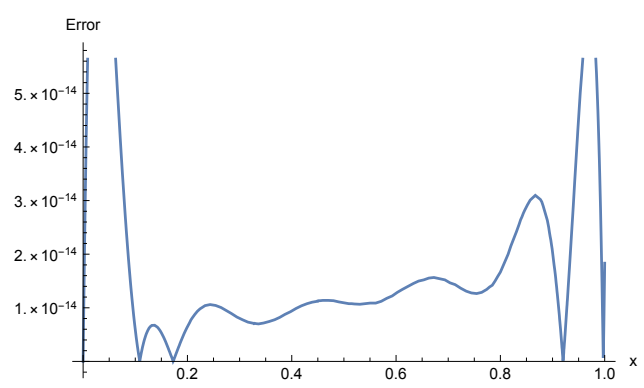

(b)

Figure 3. (a) Comparison between the solutions-(b) error function for $n=10$.

Table 7. Applying the FPA for Example 1 with $\epsilon=10^{-6}$.

\begin{tabular}{ccc}
\hline$n$ & $y_{n}(x)$ & $\left|y(x)-y_{n}(x)\right|$ \\
\hline 1 & 0.44520121812820434570 & 0.11944127082824707031 \\
2 & 0.56538361310958862305 & 0.00074112415313720703 \\
3 & 0.56462234258651733398 & 0.00002014636993408203 \\
4 & 0.56462532281875610352 & 0.00001716613769531250 \\
5 & 0.56464219093322753906 & 0.00000029802322387695 \\
\hline
\end{tabular}

Table 8. Applying the FPA to find $n$ for various $\epsilon$ and $x=0.2$.

\begin{tabular}{ccccccc}
\hline$\epsilon$ & $\epsilon<<10^{-6}$ & $\epsilon=10^{-6}$ & $\epsilon=10^{-3}$ & $\epsilon=10^{-1}$ & $\epsilon=0.5$ & $\epsilon>>0.5$ \\
\hline$n$ & $>>5$ & 5 & 2 & 1 & 1 & 1 \\
\hline
\end{tabular}

Table 9. Results of the CESTAC method for Example 3 and $x=0.6$.

\begin{tabular}{cccc}
\hline$n$ & $y_{n}(x)$ & $\left|y_{n}(x)-y_{n-1}(x)\right|$ & $\left|y(x)-y_{n}(x)\right|$ \\
\hline 1 & 0.4452011 & 0.4452011 & 0.119441 \\
2 & 0.565383 & 0.120182 & $0.7411 \times 10^{-3}$ \\
3 & 0.564622 & $0.7612 \times 10^{-3}$ & $0.20 \times 10^{-4}$ \\
4 & 0.5646252 & $0.2 \times 10^{-5}$ & $0.17 \times 10^{-4}$ \\
5 & 0.564642 & $0.16 \times 10^{-4}$ & $@ .0$ \\
6 & 0.564640 & $0.1 \times 10^{-5}$ & $0.1 \times 10^{-5}$ \\
7 & 0.5646428 & $0.2 \times 10^{-5}$ & $@ .0$ \\
8 & 0.564641 & $@ .0$ & $0.5 \times 10^{-6}$ \\
\hline
\end{tabular}

\section{Conclusions}

The VIE with a discontinuous kernel was studied. We applied the Lagrange-collocation method for solving the problem. The accuracy of the method was discussed by proving the error analysis theorem. The optimal results were obtained using the CESTAC method and the CADNA library. Additionally, the optimal results, such as the optimal step, approximation and error, were found. Comparing the results between the Lagrange-collocation method using the FPA and the SA, we can see that the SA has more advantages in comparison with the FPA.

Author Contributions: Conceptualization, S.N.; data curation, S.N. and S.M.; formal analysis, S.N.; funding acquisition, S.N.; investigation, S.N. and S.M.; methodology, S.N. and S.M.; project administration, S.N.; resources, S.N.; software, S.N.; supervision, S.N.; validation, S.N.; visualization, S.N.; writing-original draft, S.N.; writing—review and editing, S.N. and S.M. All authors have read and agreed to the published version of the manuscript.

Funding: This research received no external funding.

Institutional Review Board Statement: Not applicable. 
Informed Consent Statement: Not applicable.

Data Availability Statement: Not applicable.

Conflicts of Interest: The authors declare no conflict of interest.

\author{
Abbreviations \\ The following abbreviations are used in this manuscript: \\ VIE Volterra integral equations \\ CESTAC Controle et Estimation Stochastique des Arrondis de Calculs \\ CADNA Control of Accuracy and Debugging for Numerical Applications \\ DSA Discrete stochastic mathematic \\ NCSDs Number of common significant digits
}

\title{
References
}

1. Sidorov, D.N. On parametric families of solutions of Volterra integral equations of the first kind with piecewise smooth kernel. Differ. Equ. 2013, 49, 210-216 [CrossRef]

2. Sidorov, D.; Muftahov, I.; Karamov, D.; Tomin, N.; Panasetsky, D.; Dreglea, A.; Liu, F.; Foley, A. A Dynamic Analysis of Energy Storage with Renewable and Diesel Generation using Volterra Equations. IEEE Trans. Ind. Inform. 2020, 16, 3451-3459. [CrossRef]

3. Agarwal, R.P.; Gala, S.; Ragusa, M.A. A regularity criterion in weak spaces to Boussinesq equations. Mathematics 2020, 8, 920. [CrossRef]

4. Zhang, F.; Zhang, X.; Hao, F. Common fixed point theorems for contractive mappings of integral type in Geometric spaces and applications. J. Funct. Spaces 2021, 2021, 6619964.

5. Tofigh, A.A.C.; Khodabin, M.; Ezzati, R. Numerical Solution of Linear Stochastic Volterra Integral Equations via New Basis Functions. Filomat 2019, 33, 5959-5966.

6. Sidorov, D.; Tynda, A.; Muftahov, I.; Dreglea, A.; Liu, F. Nonlinear Systems of Volterra Equations with Piecewise Smooth Kernels: Numerical Solution and Application for Power Systems Operation. Mathematics 2020, 8, 1257. [CrossRef]

7. Tynda, A.N.; Sidorov, D.N.; Muftahov, I.R. Numerical method for systems of nonlinear Volterra integral equations of the first kind with discontinuous kernels. Zhurnal SVMO 2018, 20, 55-63. [CrossRef]

8. Sidorov, D.N.; Zhukov, A.V.; Muftahov, I.R. Volterra equation based models for energy storage usage based on load forecast in EPS with renewable generation, The Bulletin of Irkutsk State University. Ser. Math. 2018, 26, 76-90.

9. Dreglea, A.; Foley, A.; Hager, U.; Sidorov, D.; Tomin, N. Hybrid renewable energy systems, load and generation forecasting, new grids structure, and smart technologies. In Solving Urban Infrastructure Problems Using Smart City Technologies. Handbook on Planning, Design, Development, and Regulation; Vacca, J., Ed.; Elsevier: Amsterdam, The Netherlands, 2021; pp. 475-484.

10. Tao, Q.; Liu, F.; Sidorov, D. Recurrent Neural Networks Application to Forecasting with Two Cases: Load and Pollution. In Advances in Intelligent Systems and Computing; Weber, G.W., Ed.; Springer: Berlin/Heidelberg, Germany, 2020; Volume 1072, pp. 369-378.

11. Sidorov, D.; Tao, Q.; Muftahov, I.; Zhukov, A.; Karamov, D.; Dreglea, A.; Liu, F. Energy balancing using charge/discharge storages control and load forecasts in a renewable-energy-based grids. In Proceedings of the 38th China Control Conference, Guangzhou, China, 27-30 July 2019.

12. Noeiaghdam, S.; Sidorov, D.; Wazwaz, A.M.; Sidorov, N.; Sizikov, V. The numerical validation of the Adomian decomposition method for solving Volterra integral equation with discontinuous kernel using the CESTAC method. Mathematics 2021, 9, 260. [CrossRef]

13. Noeiaghdam, S.; Dreglea, A.; He, J.H.; Avazzadeh, Z.; Suleman, M.; Fariborzi Araghi, M.A.; Sidorov, D.; Sidorov, N. Error estimation of the homotopy perturbation method to solve second kind Volterra integral equations with piecewise smooth kernels: Application of the CADNA library. Symmetry 2020, 12, 1730. [CrossRef]

14. Hashemizadeh, E.; Ebadi, M.A.; Noeiaghdam, S. Matrix method by Genocchi polynomials for solving nonlinear Volterra integral equations with weakly singular kernel. Symmetry 2020, 12, 2105. [CrossRef]

15. Noeiaghdam, S.; Sidorov, D.; Sizikov, V.; Sidorov, N. Control of accuracy on Taylor-collocation method to solve the weakly regular Volterra integral equations of the first kind by using the CESTAC method. Appl. Comput. Math. Int. J. 2020, 19, 81-105.

16. Noeiaghdam, S.; Sidorov, D.; Muftahov, I.; Zhukov, A.V. Control of Accuracy on Taylor-Collocation Method for Load Leveling Problem, The Bulletin of Irkutsk State University. Ser. Math. 2019, 30, 59-72.

17. Noeiaghdam, S.; Zarei, E.; Kelishami, H.B. Homotopy analysis transform method for solving Abel's integral equations of the first kind. Ain Shams Eng. J. 2016, 7, 483-495. [CrossRef]

18. Fariborzi Araghi, M.A.; Noeiaghdam, S. Homotopy analysis transform method for solving generalized Abel's fuzzy integral equations of the first kind. In Proceedings of the 4th Iranian Joint Congress on Fuzzy and Intelligent Systems, CFIS 2015, Zahedan, Iran, 9-11 September 2016.

19. Fariborzi Araghi, M.A.; Noeiaghdam, S. A novel technique based on the homotopy analysis method to solve the first kind Cauchy integral equations arising in the theory of airfoils. J. Interpolat. Approx. Sci. Comput. 2016, 2016, 1-13. [CrossRef] 
20. Noeiaghdam, S.; Fariborzi Araghi, M.A.; Abbasbandy, S. Finding optimal convergence control parameter in the homotopy analysis method to solve integral equations based on the stochastic arithmetic. Numer. Algorithms 2019, 81, 237-267. [CrossRef]

21. Noeiaghdam, S.; Fariborzi Araghi, M.A. Application of the CESTAC Method to Find the Optimal Iteration of the Homotopy Analysis Method for Solving Fuzzy Integral Equations. In Progress in Intelligent Decision Science. IDS 2020. Advances in Intelligent Systems and Computing; Springer: Cham, Switzerland, 2021; Volume 1301.

22. Noeiaghdam, S.; Fariborzi Araghi, M.A. Homotopy regularization method to solve the singular Volterra integral equations of the first kind. Jordan J. Math. Stat. 2018, 11, 1-12.

23. Fariborzi Araghi, M.A.; Noeiaghdam, S. Fibonacci-regularization method for solving Cauchy integral equations of the first kind. Ain Shams Eng. J. 2017, 8, 363-369. [CrossRef]

24. Noeiaghdam, S.; Fariborzi Araghi, M.A. A novel approach to find optimal parameter in the homotopy-regularization method for solving integral equations. Appl. Math. Inf. Sci. 2020, 14, 105-113.

25. Noeiaghdam, S.; Fariborzi Araghi, M.A.; Abbasbandy, S. Valid implementation of Sinc-collocation method to solve the fuzzy Fredholm integral equation. J. Comput. Appl. Math. 2020, 370, 112632. [CrossRef]

26. Noeiaghdam, S.; Fariborzi Araghi, M.A. Valid implementation of the Sinc-collocation method to solve the linear integral equations by CADNA library. J. Math. Model. 2019, 7, 63-84.

27. Micula, S. A Numerical Method for Weakly Singular Nonlinear Volterra Integral Equations of the Second Kind. Symmetry 2020, 12, 1862. [CrossRef]

28. Micula, S.; Cattani, C. On a numerical method based on wavelets for Fredholm-Hammerstein integral equations of the second kind. Math. Method. Appl. Sci. 2018, 41, 9103-9115. [CrossRef]

29. Micula, S. On some iterative numerical methods for a Volterra functional integral equation of the second kind. J. Fixed Point Theory Appl. 2017, 19, 1815-1824. [CrossRef]

30. Micula, S. A fast converging iterative method for Volterra integral equations of the second kind with delayed arguments. Fixed Point Theory 2015, 16, 371-380.

31. Luo, W.; Gu, X.; Yang, L.; Meng, J. A Lagrange-quadratic spline optimal collocation method for the time tempered fractional diffusion equation. Math. Comput. Simul. 2021, 182, 1-24. [CrossRef]

32. Wang, K.; Wang, Q. Lagrange collocation method for solving Volterra-Fredholm integral equations. Appl. Math. Comput. 2013, 219, 10434-10440. [CrossRef]

33. Wang, B.; Wu, X.; Meng, F. Trigonometric collocation methods based on Lagrange basis polynomials for multi-frequency oscillatory second-order differential equations. J. Comput. Appl. Math. 2017, 313, 185-201. [CrossRef]

34. Costabile, F.A.; Napoli, A. A class of Birkhoff-Lagrange-collocation methods for high order boundary value problems. Appl. Numer. Math. 2017, 116, 129-140. [CrossRef]

35. Maleknejad, K.; Derili, H. Numerical solution of Hammerstein integral equations by using combination of spline-collocation method and Lagrange interpolation. Appl. Math. Comput. 2007, 190, 1557-1562. [CrossRef]

36. Vignes, J. Discrete Stochastic Arithmetic for Validating Results of Numerical Software. Spec. Issue Numer. Algorithms 2004, 7 , 377-390. [CrossRef]

37. Vignes, J. A stochastic arithmetic for reliable scientific computation. Math. Comput. Simul. 1993, 35, 233-261. [CrossRef]

38. Laboratoire d'Informatique de Paris 6. Available online: https://www-pequan.lip6.fr/ (accessed on 10 June 2020).

39. Noeiaghdam, L.; Noeiaghdam, S.; Sidorov, D. Dynamical Control on the Homotopy Analysis Method for Solving Nonlinear Shallow Water Wave Equation. J. Phys. Conf. Ser. 2021, 1847, 012010. [CrossRef]

40. Noeiaghdam, S.; Micula, S. Dynamical Strategy to Control the Accuracy of the Nonlinear Bio-mathematical Model of Malaria Infection. Mathematics 2021, 9, 1031. [CrossRef]

41. Noeiaghdam, S.; Sidorov, D.; Zamyshlyaeva, A.; Tynda, A.; Dreglea, A. A valid dynamical control on the reverse osmosis system using the CESTAC method. Mathematics 2021, 9, 48. [CrossRef]

42. Noeiaghdam, S.; Fariborzi Araghi, M.A. A novel algorithm to evaluate definite integrals by the Gauss-Legendre integration rule based on the stochastic arithmetic: Application in the model of osmosis system. Math. Model. Eng. Probl. 2020, 7, 577-586. [CrossRef]

43. Fariborzi Araghi, M.A.; Noeiaghdam, S. Finding the optimal step of fuzzy Newton-Cotes integration rules by using CESTAC method. J. Fuzzy Set Valued Anal. 2017, 2, 62-85.

44. Fariborzi Araghi, M.A.; Noeiaghdam, S. A valid scheme to evaluate fuzzy definite integrals by applying the CADNA library. Int J. Fuzzy Syst. Appl. 2017, 6, 1-20.

45. Fariborzi Araghi, M.A.; Noeiaghdam, S. Dynamical control of computations using the Gauss-Laguerre integration rule by applying the CADNA library. Adv. Appl. Math. Sci. 2016, 16, 1-18.

46. Fariborzi Araghi, M.A.; Noeiaghdam, S. Validation of Numerical Algorithms: Stochastic Arithmetic; Entekhab Bartar Publisher: Tehran, Iran, 2021; ISBN 978-622-6498-09-8.

47. Jézxexquel, F.; Mecanique, C.R. A dynamical strategy for approximation methods. Comptes Rendus Mec. 2006, $334,362-367$. [CrossRef]

48. Graillat, S.; Jézxexquel, F.; Wang, S.; Zhu, Y. Stochastic arithmetic in multi precision. Math. Comput. Sci. 2011, 5, 359-375. [CrossRef] 
49. Graillat, S.; Jézxexquel, F.; Picot, R. Numerical Validation of Compensated Summation Algorithms with Stochastic Arithmetic. Electron. Notes Theor. Comput. Sci. 2015, 317, 55-69. [CrossRef]

50. Chesneaux, J.M. CADNA, an ADA tool for round-off error analysis and for numerical debugging. In Proceedings of the Congress on ADA, Aerospace, Barcelona, Spain, 20-25 May 1990.

51. Chesneaux, J.M.; Jézxexquel, F. Dynamical control of computations using the Trapezoidal and Simpson's rules. J. Univers. Comput. Sci. 1998, 4, 2-10. 